\title{
DETERMINAÇÃO DA COMPOSIÇÃO QUÍMICA E DOS VALORES DE ENERGIA METABOLIZÁVEL DE ALGUNS ALIMENTOS PROTEICOS PARA FRANGOS DE CORTE
}

\section{DETERMINATION OF CHEMICAL COMPOSITION AND METABOLIZABLE ENERGY VALUES OF SOME PROTEIN FEEDS FOR BROILER CHICKEN}

\author{
Bruno Andreatta Scotta ${ }^{1^{*}}$ \\ Luiz Fernando Teixeira Albino ${ }^{1}$ \\ Paulo Cezar Brustolini ${ }^{1}$ \\ Ana Paula Cardoso Gomide ${ }^{1}$ \\ Priscila Furtado Campos ${ }^{1}$ \\ Valeria Vania Rodrigues ${ }^{1}$ \\ ${ }^{1}$ Universidade Federal de Viçosa, Viçosa, MG, Brasil. \\ *Contato para correspondência - brunoandreattascotta@hotmail.com
}

\section{Resumo}

Foi realizado um experimento, utilizando-se o método tradicional de coleta total de excretas, com o objetivo de determinar os valores de energia metabolizável aparente, energia metabolizável aparente corrigida pelo balanço de nitrogênio e composição química de seis alimentos: soja integral desativada com casca, soja integral desativada sem casca, concentrado proteico de soja, farelo de soja extrusada semi-integral, farelo de soja e glúten de trigo. Foram utilizados 252 pintos de corte da linhagem comercial Cobb 500, com 14 dias de idade, distribuídos em delineamento inteiramente casualizado, com sete tratamentos (seis rações testes e uma ração referência), seis repetições e seis aves por unidade experimental. Os cinco dias iniciais foram destinados à adaptação das aves às rações experimentais e os cinco dias finais à coleta total das excretas, realizada duas vezes ao dia. Os valores de energia metabolizável aparente corrigida pelo balanço de nitrogênio na matéria natural determinados em frangos de corte no período de 14 a 24 dias de idade foram os seguintes: soja integral desativada com casca: $2797 \mathrm{kcal} / \mathrm{kg}$; soja integral desativada sem casca: $3012 \mathrm{kcal} / \mathrm{kg}$; concentrado proteico de soja: $2554 \mathrm{kcal} / \mathrm{kg}$; farelo de soja extrusada semi-integral: $2467 \mathrm{kcal} / \mathrm{kg}$; farelo de soja: $2221 \mathrm{kcal} / \mathrm{kg}$; glúten de trigo: $3813 \mathrm{kcal} / \mathrm{kg}$.

Palavras-chave: concentrado proteico de soja; farelo de soja; farelo de soja extrusada semi-integral; glúten de trigo; soja integral desativada

\begin{abstract}
We conducted a biological assay using the traditional method of excreta collection, with the purpose to determine the values of apparent metabolizable energy, apparent metabolizable energy corrected for nitrogen balance, and the chemical composition of six feeds: deactivated whole soybean with shuck; deactivated whole soybean without shuck; soy protein concentrate; extruded semi-whole soybean meal; soybean meal; and wheat gluten. We used 252 chicks of the Cobb 500 commercial lineage, from 14 to 24 days of age, distributed in a completely randomized design, with seven treatments (six test rations and a reference ration) and six repetitions with six birds per experimental unit. The five initial days were destined to the adaptation of the birds to the experimental rations, and the five final days were destined to excreta collection, which was carried out twice a day. The values of apparent
\end{abstract}


metabolizable energy corrected for nitrogen balance, based on natural matter determined in broiler chicken aged from 14 to 24 days old were as follows: deactivated whole soybean with shuck: 2797 $\mathrm{kcal} / \mathrm{kg}$; deactivated whole soybean without shuck: $3012 \mathrm{kcal} / \mathrm{kg}$; soy protein concentrate:, $2554 \mathrm{kcal} /$ $\mathrm{kg}$; extruded semi-whole soybean meal: $2467 \mathrm{kcal} / \mathrm{kg}$; soybean meal: $2221 \mathrm{kcal} / \mathrm{kg}$ and wheat gluten: $3813 \mathrm{kcal} / \mathrm{kg}$.

Keywords: deactivated whole soybean; extruded semi-whole soybean meal; soy protein concentrate; soybean meal; wheat gluten.

Enviado em: 30 novembro de 2011

Aceito em: 31 agosto 2016

\section{Introdução}

O Brasil apresenta grande diversidade de alimentos e de subprodutos que podem ser utilizados na alimentação animal. Porém variações nas composições nutricionais dos alimentos de origem vegetal podem ocorrer, devido principalmente à região geográfica onde o alimento é cultivado, às condições de plantio, à fertilidade do solo, à variabilidade genética dos cultivares, às formas de armazenamento e ao processamento dos grãos, entre outros ${ }^{(1)}$.

O conhecimento da composição química dos alimentos é ponto importante no processo de formulação de rações para os animais de produção, isso permitirá ao nutricionista utilizar quantidades corretas de nutrientes, formulando, assim, rações viáveis e evitando a deficiência ou o excesso de nutrientes nas rações.

A energia presente nos alimentos pode ser definida como uma unidade de calor ou caloria, sendo uma caloria igual à quantidade de calor necessária para elevar 1 grama de água de $14{ }^{\circ} \mathrm{C}$ para $15{ }^{\circ} \mathrm{C}$. A caloria não pode ser considerada um nutriente, mas sim o resultado da oxidação dos nutrientes durante o metabolismo animal, principalmente da proteína, carboidratos, lipídeos e parte da fibra. A energia é um dos fatores limitantes do consumo de alimento ${ }^{(2)}$ e está envolvida em todos os processos produtivos das aves. Além de influenciar no consumo de ração e no nível energético das dietas, também influencia no desempenho das aves e no custo das rações.

Os valores de energia metabolizável dos alimentos podem variar de acordo com a metodologia utilizada para determiná-la ${ }^{(3)}$, a retenção de nitrogênio, a espécie de ave ${ }^{(4)}$, a idade das aves ${ }^{(5)}$, o processamento ${ }^{(6)}$, a granulometria da ração, o nível de inclusão do alimento testado, o sexo das aves, o consumo de ração, a adição de enzimas exógenas à $\operatorname{dieta}^{(7)}$, entre outros fatores; daí a necessidade constante de avaliação dos valores de energia metabolizável dos alimentos nas mais diferentes situações.

Portanto, objetivou-se determinar a composição química e os valores de energia metabolizável aparente (EMA) e aparente corrigida pelo balanço de nitrogênio (EMA ${ }_{n}$ ) de alguns alimentos proteicos para frangos de corte.

\section{Materiais e Métodos}

O experimento foi realizado no setor de Avicultura do Departamento de Zootecnia da Universidade Federal de Viçosa-MG, no período de 17/10/2011 a 26/10/2011, com a finalidade de determinar os valores de energia metabolizável aparente (EMA) e de energia metabolizável aparente corrigida para o balanço de nitrogênio $\left(\mathrm{EMA}_{\mathrm{n}}\right)$ de seis alimentos proteicos.

O método que foi utilizado para a determinação dos valores de EMA e EMA foi o de coleta total de excretas, com pintos na fase de crescimento durante o período de 14 a 24 dias de idade. Os animais 
foram alojados do primeiro aos 13 dias de idade em galpão de alvenaria e então transferidos para as baterias, onde foi realizado o ensaio biológico. Foram utilizados 252 frangos de corte, machos, da linhagem Cobb 500, distribuídos em delineamento experimental inteiramente casualizado, com sete tratamentos (seis rações testes e uma ração referência), seis repetições e seis aves por unidade experimental.

A ração referência foi à base de milho e de farelo de soja (Tabela 1). Os alimentos testados foram: soja integral desativada com casca, soja integral desativada sem casca, concentrado proteico de soja, farelo de soja extrusado semi-integral, farelo de soja e glúten de trigo, que substituíram a ração referência na proporção de $30 \%$, constituindo assim as seis rações testes.

As rações foram fornecidas à vontade por um período de dez dias, sendo os primeiros cinco dias para adaptação às rações experimentais e ao ambiente e os últimos cinco dias para a coleta total das excretas de cada unidade experimental. As rações de cada unidade experimental foram acondicionadas em baldes plásticos durante o período de coleta e, ao final desse período, as sobras de rações nos baldes foram pesadas para determinação do consumo de ração.

Tabela 1. Composição da ração referência, em percentagem da matéria natural

\begin{tabular}{|c|c|}
\hline Ingredientes & $\%$ \\
\hline Milho & 55,300 \\
\hline Farelo de Soja & 37,920 \\
\hline Óleo de Soja & 2,940 \\
\hline Fosfato Bicálcico & 1,820 \\
\hline Calcário & 0,840 \\
\hline Sal Comum & 0,490 \\
\hline DL-metionina ( $99 \%)$ & 0,236 \\
\hline L-lisina $\mathrm{HCl}(78,4 \%)$ & 0,099 \\
\hline L-treonina $(98 \%)$ & 0,010 \\
\hline Suplemento Vitamínico ${ }^{1}$ & 0,120 \\
\hline Suplemento Mineral $^{2}$ & 0,050 \\
\hline Cloreto de Colina $60 \%$ & 0,100 \\
\hline Anticoccidiano $^{3}$ & 0,055 \\
\hline Antioxidante ${ }^{4}$ & 0,010 \\
\hline Total & 100,000 \\
\hline \multicolumn{2}{|l|}{ Composição calculada } \\
\hline Energia Metabolizável (Kcal/Kg) & 3110 \\
\hline Proteína Bruta (\%) & 22,140 \\
\hline Lisina digestível (\%) & 1,160 \\
\hline Metionina digestível (\%) & 0,540 \\
\hline Metionina + Cistina digestível (\%) & 0,835 \\
\hline Treonina digestível (\%) & 0,754 \\
\hline Triptofano digestivel (\%) & 0,245 \\
\hline Cálcio (\%) & 0,884 \\
\hline Fósforo disponivel (\%) & 0,450 \\
\hline Sódio (\%) & 0,214 \\
\hline \multicolumn{2}{|c|}{ 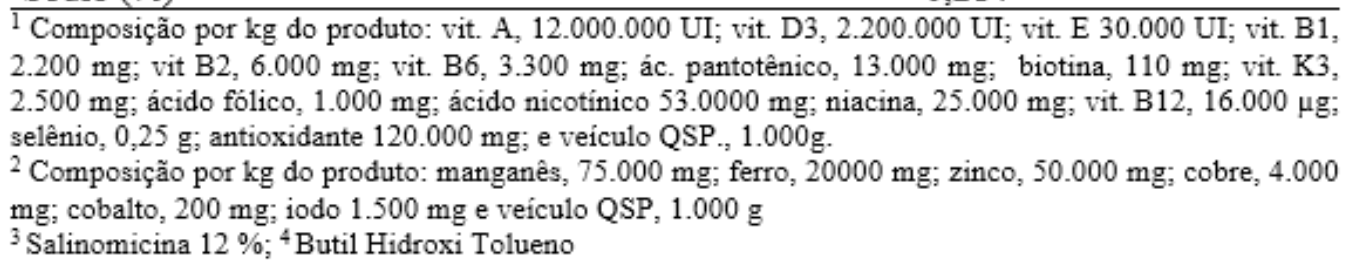 } \\
\hline
\end{tabular}


As coletas das excretas foram realizadas duas vezes ao dia (às oito horas e às dezesseis horas) para evitar fermentação, o que levaria à perda de nutrientes e consequentemente de energia, e as bandejas utilizadas para as coletas foram revestidas com plástico e colocadas sob o piso de cada unidade experimental.

As excretas coletadas foram acondicionadas em sacos plásticos, devidamente identificados e posteriormente armazenados em freezer até o final do período de coleta. Terminado o período experimental, as amostras de excretas foram pesadas, homogeneizadas e retiradas alíquotas de 200 gramas de cada unidade experimental, as quais foram submetidas à secagem e moagem para as devidas análises laboratoriais (matéria seca, nitrogênio e energia bruta) no laboratório de Nutrição Animal do Departamento de Zootecnia da Universidade Federal de Viçosa, segundo técnicas descritas por Silva \& Queiroz ${ }^{(8)}$.

Obtidos os resultados das análises laboratoriais dos alimentos, da ração referência, das rações testes e das excretas e baseado no consumo de ração e produção total de excretas, foram calculados os valores de energia metabolizável aparente (EMA) e energia metabolizável aparente corrigida (EMA $)$, por meio de equações, propostas por Matterson et al. ${ }^{(9)}$.

Para a determinação da composição química dos alimentos avaliados, foram realizadas as análises de matéria seca, energia bruta, nitrogênio, extrato etéreo, fibra bruta, fibra em detergente neutro, fibra em detergente ácido, matéria mineral, cálcio e fósforo no Laboratório de Nutrição Animal do Departamento de Zootecnia da Universidade Federal de Viçosa, segundo técnicas descritas por Silva \& Queiroz $^{(8)}$.

O trabalho foi avaliado e aprovado pela Comissão de Ética no uso de animais do Departamento de Zootecnia da Universidade Federal de Viçosa em 26/03/2012 pelo processo $n^{\circ}$ 8/2012 e está de acordo com os princípios éticos da experimentação animal, estabelecido pelo Colégio Brasileiro de Experimentação Animal e com a legislação vigente.

\section{Resultados e Discussão}

Os valores de composição química com base na matéria natural dos alimentos avaliados estão apresentados na Tabela 2 .

Foram observadas diferenças nos valores de composição química dos alimentos quando comparados com a literatura, o que já era esperado, pois a composição química dos alimentos pode ser influenciada por fatores como a região geográfica, as condições de plantio, a fertilidade do solo, a variabilidade genética dos cultivares, as formas de armazenamento e o processamento dos grãos, entre outros ${ }^{(1)}$.

Dois tipos de soja integral desativada foram estudados, a soja integral desativada com casca (SIDCC) e a soja integral desativada sem casca (SIDSC). A presença ou não da casca levou a diferenças na composição química desses alimentos, sendo que os valores de fibra bruta (FB), fibra em detergente neutro (FDN) e fibra em detergente ácido (FDA) da SIDCC foram 24,69\%, 11,08\% e 17,77\%, respectivamente, superiores ao da SIDSC.

Os valores de proteína bruta $(\mathrm{PB})$ e fósforo $(\mathrm{P})$ das duas sojas integrais desativadas estudadas foram superiores, os de matéria mineral $(\mathrm{MM})$ e cálcio $(\mathrm{Ca})$ foram iguais aos encontrados por Calderano et al. ${ }^{(10)}$, e os valores de extrato etéreo (EE) foram superiores ao determinado por Freitas et al. ${ }^{(11)}$. Os valores de fibra bruta (FB), fibra em detergente neutro (FDN), fibra em detergente ácido (FDA) e energia bruta (EB) foram inferiores aos encontrados por Calderano et al. ${ }^{(10)}$. O teor de PB do CPS foi igual ao observado por Rostagno et al. ${ }^{(12)}$, os valores do EE superior e os de $\mathrm{MM}$, Ca e P inferiores ao observado por Brumano et al. ${ }^{(13)}$.

O farelo de soja extrusado semi-integral apresentou valores de composição química diferentes quando comparado ao farelo de soja integral testado por Calderano et al. ${ }^{(10)}$, que obtiveram valores inferiores 
de PB (37,07\%) e superiores de EE (17,67\%). Esse valor inferior para o EE quando a soja extrusada semi-integral é comparada à soja extrusada integral já era esperado, visto que a soja extrusada semiintegral, após passar pelo processo de extrusão, é prensada retirando-se parte do óleo nela contido, reduzindo seu valor de EE.

Tabela 2. Composição química e bromatológica dos alimentos avaliados expressos em porcentagem (\%) na matéria natural

\begin{tabular}{llllllllll}
\hline & MS & PB & EE & MM & Ca & P & FB & FDN & FDA \\
\hline SIDCC & 90,76 & 37,56 & 23,49 & 4,50 & 0,21 & 0,56 & 4,86 & 25,54 & 18,63 \\
SIDSC & 90,82 & 38,60 & 23,31 & 4,44 & 0,22 & 0,59 & 3,66 & 22,71 & 15,32 \\
CPS & 89,26 & 64,14 & 1,16 & 5,42 & 0,33 & 0,70 & 2,63 & 12,75 & 6,59 \\
FSESI & 89,92 & 45,14 & 8,75 & 5,23 & 0,28 & 0,58 & 6,21 & 16,32 & 11,87 \\
FS & 88,41 & 45,59 & 2,25 & 5,75 & 0,28 & 0,59 & 5,38 & 13,56 & 7,86 \\
GT & 92,80 & 73,28 & 1,72 & 0,51 & 0,14 & 0,20 & 1,13 & 5,27 & 9,62 \\
\hline
\end{tabular}

SIDCC (Soja Integral Desativada com Casca); SIDSC (Soja Integral Desativada sem Casca); CPS (Concentrado Proteico de Soja); FSESI (Farelo de Soja Extrusada Semi-Integral); FS (Farelo de Soja); GT (Glúten de Trigo); MS (Matéria Seca); PB (Proteína Bruta); EE (Extrato Etéreo); MM (Matéria Mineral); Ca (Cálcio); P (Fósforo); FB (Fibra Bruta); FDN (Fibra em Detergente Neutro); FDA (Fibra em Detergente Ácido).

O valor de EE para o FS foi superior em 42,22\% quando comparado ao valor encontrado por Mello et al. ${ }^{(14)}$ assim como os teores de FB e FDA, mas o teor de FDN foi inferior. Zonta et al. ${ }^{(15)}$ também observaram teores superiores de EE para as cinco amostras diferentes de farelo de soja testadas por eles, mas valores similares de FB, FDA e FDN.

O glúten de trigo apresentou valor de PB de $73,28 \%$, superior ao teor de PB do glúten de milho, que foi de $61,07 \%^{(12)}$, sendo este $16,66 \%$ inferior ao glúten de trigo. Os valores de MM, P e FDN foram inferiores em $67,72 \%, 55,55 \%$ e $34,53 \%$, respectivamente, aos valores observados por Brumano et al. ${ }^{(13)}$ para o glúten de trigo. Os valores de EE e FB foram iguais, já os valores de FDA e Ca foram inferiores ao observado pelo último.

Os valores de energia bruta (EB), energia metabolizável aparente (EMA) e energia metabolizável corrigida para o balanço de nitrogênio $\left(\mathrm{EMA}_{\mathrm{n}}\right)$, com seus respectivos desvios padrões da média, estão apresentados na Tabela 3.

Para todos os alimentos avaliados, os valores de EMA foram superiores aos valores de EMA indicando que as aves, durante o período experimental, apresentaram balanço de nitrogênio positivo, que se caracteriza pela retenção do nitrogênio presente no alimento. Segundo Nery et al. ${ }^{(16)}$, quando os valores de energia metabolizável são determinados pelo método tradicional de coleta com pintos, é normal que ocorra maior retenção de nitrogênio, pois os animais estão em crescimento e necessitam desse nitrogênio para deposição de tecido proteico. Lopes \& Lesson ${ }^{(17)}$ observaram um significativo aumento diário na retenção de nitrogênio de frangos de corte com o avançar da idade dos mesmos, mas somente até a idade de 28 dias. Após esse período, a retenção de nitrogênio teve uma queda, indicando que animais em crescimento necessitam de mais nitrogênio devido à mais intensa deposição de tecido proteico quando comparados com animais mais velhos.

O balanço de nitrogênio pode ser positivo ou negativo. Quando positivo, os valores de EMA são superiores aos valores de $\mathrm{EMA}_{\mathrm{n}}$, o que indica retenção de nitrogênio e deposição proteica. E quando negativo, os valores de EMA são inferiores aos valores de $\mathrm{EMA}_{\mathrm{n}}$, indicando degradação proteica. 
Tabela 3. Valores de energia bruta (EB), energia metabolizável aparente (EMA) e energia metabolizável aparente corrigida para o balanço de nitrogênio $\left(\mathrm{EMA}_{\mathrm{n}}\right)$ dos alimentos, expressos na matéria natural

\begin{tabular}{lccccc}
\hline & EB (Kcal/kg) & EMA (Kcal/kg) & DP1 & EMAn (Kcal/kg) & DP2 \\
\hline SIDCC & 4580 & 2924 & 68,83 & 2797 & 118,98 \\
SIDSC & 4945 & 3236 & 71,85 & 3012 & 61,69 \\
CPS & 4323 & 2608 & 75,03 & 2554 & 84,98 \\
FSESI & 4509 & 2656 & 174,35 & 2467 & 142,32 \\
FS & 4179 & 2346 & 186,43 & 2221 & 179,58 \\
GT & 5299 & 3943 & 34,69 & 3813 & 72,57 \\
\hline
\end{tabular}

SIDCC (Soja Integral Desativada com Casca); SIDSC (Soja Integral Desativada sem Casca); CPS (Concentrado Proteico de Soja); FSESI (Farelo de Soja Extrusada Semi-Integral); FS (Farelo de Soja); GT (Glúten de Trigo); EB (Energia Bruta); EMA (Energia Metabolizável Aparente); EMAn (Energia Metabolizável Corrigida para o Balanço de Nitrogênio); DP1 (Desvio Padrão da Média para a EMA); DP2 (Desvio Padrão da Média para a $\mathrm{EMA}_{\mathrm{n}}$ ).

Os valores energéticos dos alimentos avaliados apresentaram variação em relação à literatura consultada, o que pode ser causado por diversos fatores. Segundo Borges et al. ${ }^{(18)}$, o nível de ingestão de alimento pode afetar diretamente no teor de energia metabolizável dos alimentos, assim como o conteúdo de PB e de EE, o tipo de processamento ${ }^{(19)}$, a idade das aves ${ }^{(20,21)}$ e os níveis de inclusão do alimento na dieta.

O valor de EB encontrado para SIDSC foi superior em 7,38\% ao da SIDCC. A SIDCC apresentou valores de EMA e EMA inferiores ao observado por Calderano et al. ${ }^{(10)}$ - EMA: $3232 \mathrm{kcal} / \mathrm{kg}$ e $\mathrm{EMA}_{\mathrm{n}}: 3016 \mathrm{kcal} / \mathrm{kg}$ para a faixa de idade em que os animais se encontravam. Os valores da SIDSC foram iguais, indicando que a presença da casca na soja integral desativada causa redução nos valores de EMA e EMA. Quanto maior o teor de fibra do alimento, mais rápida é a taxa de passagem do alimento pelo trato gastrintestinal, o que diminui o tempo para que o processo digestivo e absortivo dos nutrientes ocorra, levando a uma menor digestão e absorção dos alimentos e com isso menor quantidade de energia metabolizável.

A EB encontrada para o CPS foi inferior ao valor observado por Rostagno et al. ${ }^{(12)}$. Esses mesmos autores encontraram valor de EMA para o concentrado proteico de soja de $2621 \mathrm{kcal} / \mathrm{kg}$, superior ao observado. Já Brumano et al. ${ }^{(13)}$ encontraram valor de EMA de $2060 \mathrm{kcal} / \mathrm{kg}$ e de EMA de $2043 \mathrm{kcal} /$ $\mathrm{kg}$, ambos inferiores ao observado para o CPS.

O FSESI apresentou valor de EB inferior ao encontrado por Calderano et al. ${ }^{(10)}$, que foi de $5139 \mathrm{kcal} /$ $\mathrm{kg}$. O valor de EMA encontrado por Rostagno et al. ${ }^{(12)}$ foi $5,51 \%$ superior ao observado. Zonta et al. ${ }^{(22)}$ verificaram um valor de EMA para a soja integral extrusada muito superior ao observado no presente trabalho, indicando que a retirada do óleo da soja, quando se trabalhou com o produto semi-integral em detrimento ao produto integral, levou a uma queda no valor de EMA, o que já era esperado, visto que o óleo é o nutriente que apresenta maior valor energético e isto influencia diretamente o teor de EMA.

$\mathrm{O}$ valor de EB encontrado para o farelo de soja foi superior ao encontrado por Generoso et al. ${ }^{(23)}$. Os valores de EMA e EMA foram superiores aos encontrados por Rostagno et al. ${ }^{(12)}$, Mello et al..$^{(14)}$ e Generoso et al. ${ }^{(23)}$. Isso se deve possivelmente ao maior valor de EE do farelo de soja testado em relação aos demais, já que o teor de EE é um dos fatores que podem alterar o valor energético dos alimentos.

Silva et al. ${ }^{(24)}$ observaram maior teor de EMA para o farelo de soja testado por eles para poedeiras comerciais com 41 semanas de idade. $\mathrm{O}$ valor de EE observado por esses autores foi de 2,61\%, bem 
próximo ao valor obtido neste trabalho, indicando que outros fatores como a aptidão produtiva da ave e a idade também podem afetar o valor de EMA $_{n}$ dos alimentos.

O teor de EB do glúten de trigo foi 5,39\% superior ao teor de EB do glúten de milho descrito por Brumano et al. ${ }^{(13)}$. Rostagno et al. ${ }^{(12)}$ encontraram valor de EMA para o glúten de milho de $3696 \mathrm{kcal} /$ $\mathrm{kg}$, inferior ao valor encontrado para o glúten de trigo. Brumano et al. ${ }^{(13)}$ observaram valores de EMA $_{\mathrm{n}}$ de $3608 \mathrm{kcal} / \mathrm{kg}$ para o glúten de milho, também inferior ao encontrado para o glúten de trigo, e Alamo et al. ${ }^{(25)}$, trabalhando com diferentes variedades de trigo, observaram teores inferiores de EMA para todas as variedades de trigo estudadas quando o farelo de trigo oriundo dessas variedades foi utilizado na alimentação de frango de corte. Isso indica que o teor energético do glúten de trigo é superior ao do glúten de milho e ao do farelo de trigo.

\section{Conclusão}

Os valores de composição química apresentaram diferenças em relações aos valores já descritos na literatura, indicando que as análises dos alimentos devem ser constantes para uma correta formulação de rações.

Os resultados de EMA $\mathrm{n}_{\mathrm{n}}$ com base na matéria natural determinados com frangos de corte no período de 14 a 24 dias de idade são: soja integral desativada com casca, $2797 \mathrm{kcal} / \mathrm{kg}$; soja integral desativada sem casca, $3012 \mathrm{kcal} / \mathrm{kg}$; concentrado proteico de soja, $2554 \mathrm{kcal} / \mathrm{kg}$; farelo de soja extrusada semiintegral, $2467 \mathrm{kcal} / \mathrm{kg}$; farelo de soja, $2221 \mathrm{kcal} / \mathrm{kg}$; glúten de trigo, $3813 \mathrm{kcal} / \mathrm{kg}$.

\section{Agradecimentos}

Os autores agradecem à FAPEMIG (Fundação de Amparo à Pesquisa do Estado de Minas Gerais) pela ajuda financeira para a condução do experimento.

\section{Referências}

1. Nagata AK, Rodrigues PB, Freitas RTF, Bertechini AG, Fialho ET. Energia metabolizável de alguns alimentos energéticos para frangos de corte determinada por ensaios metabólicos e por equações de predição. Ciênc. Agrotec. 2004 mai-jun; 28(3):668-677.

2. Mirzaee M, Torki M, Habibian M. Effects of wheat cultivar, metabolizable energy level and xylanase supplementation to laying hens diet on performance, egg quality traits and selected blood parameters. Span. J. Agric. Res. 2014; 12(4):1071-1081.

3. Freitas ER, Sakomura NK, Ezequiel JMB, Neme R, Mendonça MO. Energia metabolizável de alimentos na formulação de ração para frangos de corte. Pesq. agropec. bras. 2006 jan. 41(1):107-115.

4. Silva RB, Freitas ER, Fuentes MFF, Lopes IRV, Lima RC, Bezerra RM. Composição química e valores de energia metabolizável de subprodutos agroindustriais determinados com diferentes aves. Acta Sci. Anim. Sci. 2008; 30(3):269-275.

5. Sharifi SD, Golestani G, Yaghobfar A, Khadem A, Pashazanussi H. Effects of supplementing a multienzyme to broiler diets containing a high level of wheat or canola meal on intestinal morphology and performance of chickes. J. Appl. Poult. Res. 2013; 22:671-679.

6. Félix AP, Zanata CP, Brito CBM, Sá Fortes CML, Oliveira SG, Maiorka A. Digestibility and metabolizable energy of raw soybeans manufactured with different processing treatments and fed to adult dogs and puppies. J. Anum. Sci. 2013; 91:2794-2801.

7. Shahir MH, Moradi S, Afsarian O, Esmaeilipour O. Effects of cereal type, enzime and sodium butyrate 
addition on growth performance, carcass traits and intestinal morphology of broilers. Bras. J. Poult. Sci. 2013 jul-set; 15(3):169-189.

8. Silva DJ, Queiroz AC. Análise de Alimentos (Métodos químicos e biológicos), 3.ed. Viçosa: Universidade Federal de Viçosa, 2002.

9. Matterson LD, Potter LM, Stutz MW. The metabolizable energy of feed ingredients for chickens. Universit of Connecticut Storrs. 11.ed. Agricultural Experiment Station Research Report, 1965.

10. Calderano AA, Gomes PC, Albino LFT, Rostagno HS, Souza RM, Mello HHC. Valores de composição química e de energia de alimentos de origem vegetal determinados com aves de diferentes idades. R. Bras. Zootec. 2010 fev; 39(2):320-326.

11. Freitas ER, Sakomura NK, Neme R, Santos AL, Fernandes JBK. Efeito do processamento da soja integral sobre a digestibilidade dos aminoácidos para aves. R. Bras. Zootec. 2005 nov-dez; 34(6): 1938-1949.

12. Rostagno HS, Albino LFT, Donzele JL, Gomes PC, Oliveira RFM, Lopes DC, Ferreira AS, Barreto SLT, Euclides RF. Tabelas brasileiras para aves e suínos: composição de alimentos e exigências nutricionais. 1.ed. Viçosa: Universidade Federal de Viçosa, 2011.

13. Brumano G, Gomes PC, Albino LFT, Rostagno HS, Generoso RAR, Schmidt M. Composição química e valores de energia metabolizável de alimentos proteicos para frangos de corte em diferentes idades. R. Bras. Zootec. 2006 nov-dez; 35(6):2297-2302.

14. Mello HHC, Gomes PC, Rostagno HS, Albino LFT, Souza RM, Calderano AA. Valores de energia metabolizável de alguns alimentos obtidos com aves de diferentes idades. R. Bras. Zootec., 2009 mai; 38(5):863-868.

15. Zonta MCM, Rodrigues PB, Zonta A, Pereira CR. Energia metabolizável de farinhas de soja ou produtos de soja determinada pelo método de coleta total ou por equações de predição. Arch. Zootec. 2006; 55(209):2130.

16. Nery LR, Albino LFT, Rostagno HS, Campos AMA, Silva CR. Valores de energia metabolizável de alimentos determinados com frangos de corte. R. Bras. Zootec. 2007; 35(5):1354-1358.

17. Lopez G, Lesson S. Relevance of nitrogen correction for assessment of metabolizable energy with broilers to forty-nine days of age. Poultry Science. 2007; 86:1696-1704.

18. Borges FMO, Rostagno HS, Saad CEP. Efeito do consumo de alimento sobre os valores energéticos do grão de trigo e seus subprodutos para frangos de corte, obtidos pela metodologia da alimentação forçada. Ciênc. Agrotec. 2004 nov-dez; 28 (6):1392-1399.

19. Leite JLB, Rodrigues PB, Fialho ET, Freitas RTF, Nagata AK, Cantarelli VS. Efeito da peletização e adição de enzimas e vitaminas sobre o desempenho e aproveitamento da energia e nutrientes em frangos de corte de 1 a 21 dias de idade. Ciênc. agrotec. 2008 jul-ago; 32(4):1292-1298.

20. Santos ALS, Gomes AVC, Pessoa MF, Mostafá S, Araújo AHB, Vieira AA. Composição química e valores energéticos de fontes proteicas em codornas de corte em diferentes idades. Ciênc. Anim. 2006 mai-jun; 36(3):930-935.

21. Romero LF, Parsons CM, Utterback PL, Plemstead PW, Ravindran V. Comparative effects of dietary carbohydrases without or with protease on ileal digestibility of energy and amino acids and $\mathrm{AME}_{\mathrm{n}}$ in young broilers. Anim. Feed Sci. Tech. 2013; 181:35-44.

22. Zonta MCM, Rodrigues PB, Zonta A, Freitas RTF, Bertechini AG, Fialho ET, pereira CR. Energia metabolizável de ingredientes proteicos determinados pelo método de coleta total e por equações de predição. Ciênc. Agrotec. 2004 nov-dez; 28(6):1400-1407.

23. Generoso RAR, Gomes PC, Rostagno HS, Albino LFT, Barreto SLT, Brumano G. Composição química e energética de alguns alimentos para frangos de corte em duas idades. R. Bras. Zootec. 2008 jul; 37(7):22972302.

24. Silva EP, Rabello CB, Lima MB, Loureiro RRS, Guimarães AAS, Dutra Junior WM. Valores energéticos de ingredientes convencionais para aves de postura comercial. Ciênc. Anim. Bras. 2009 jan-mar; 10(1):91-100.

25. Alamo AG, Verstegen MWA, Den Hartog LA, Ayala PP, Villamide MJ. Effect of wheat cultivar and enzyme addition to broiler chicken diets on nutrient digestibility, performance and apparent metabolizable energy content. Poultry Science. 2008; 87:759-767. 